\title{
Computer Education's Teaching-Learning Methods Using Educational Programming Language Based on STEAM Education*
}

\author{
Namje Park ${ }^{* *}$ and Yeonghae Ko \\ Department of Computer Education, Teachers College, \\ Jeju National University, Jeju, Korea \\ \{namjepark, smakor\}@jejunu.ac.kr
}

\begin{abstract}
STEAM is an acronym of Science, Technology, Engineering, Arts, and Mathematics. To realize the STEAM education, the factors on how to interrelate and integrate science, technology, engineering, art, and mathematics as well as the factors that are needed in realizing the STEAM education in creativity in addition to the considered factors in contents need to be decided, which in reality, makes the creation of STEAM materials into a system science or system engineering. This paper analyzed the statuses of STEAM education. And, suggested factors to realize successful STEAM education materials.
\end{abstract}

Keywords: STEAM, Computer education, EPL, Science, Technology.

\section{Introduction}

In June of 2005, the U.S. President's Information Technology Advisory Committee (PITAC) projected that the Computational Science is the most needed and important field in the 21st century academics. In addition, the Association of Computing Machinery (ACM) in May of 2011 pointed out that despite the great contribution of computational sciences not only on the economy but also on the technology that has renovated the general society, the number of students who major in computational sciences has decreased and the interests in K-12 education are also low. As its solution, they advise that the computational sciences and IT need to be mixed in actual learning and the political basis to cultivate licensed teachers need to be established. In other words, the computational sciences education is argued to be the crucial and key education to bring up the global leaders in the elementary school education.

Such computational sciences and IT education can also be found in the concept of STEAM education. Yakman defined the boundaries of Science (S), Technology (T), Engineering (E), Arts (A), and Mathematics (M) in STEAM education. He suggested that the contents of computational sciences belong to the Computer in Engineering

\footnotetext{
* This work was supported by the Korea Foundation for the Advancement of Science \& Creativity(KOFAC) grant funded by the Korean Government(MEST).

** Corresponding author.
} 
(E) field and the contents of IT belong to informational technology under Technology

(T). The STEAM education using IT is an attractive educational method for the digital generation students to easily and pleasantly learn the contents of mathematics, sciences, and technology. The educational methods that integrate IT and other fields of academia have been attempted before STEAM education. In addition, the reason for a brighter footlight for IT as the transition from STEM education to STEAM education occurs is that occupy a large section in the field of Art in the digital era. Korea also needs to reflect such international standardization trends of NFC standardization and also create an appropriate connection platform for Korea through a comparative analysis with the domestic standardization of mobile RFID technology. In addition, the new standardizations need to be reflected internationally in an active manner. For these reasons, this report provides the foundation for domestic distribution of related technologies and standardizations by connecting the two technologies through the analysis of NFC system international standardization activities and trends with mobile RFID technology.

\section{STEAM Education}

\subsection{STEAM Concept}

STEAM is an acronym of Science, Technology, Engineering, Arts, and Mathematics. This is an educational curriculum that combined Art to the existing American STEM (Science, Technology, Engineering, Mathematics) curriculum and Yakman (2008) defined the STEAM education in the following two directions.

First, it is an education where Science, Technology, engineering, and mathetmatics include other areas in addition to the standards of their own and second, it is an integrative education that purposefully includes the actual subjects and teaching matters. For a more detailed definition, Yakman (2008) suggested the framework. As shown in the framework, the STEAM education determines the level from the lifelong learning to detailed academic content classification. The first level is the Lifelong learning. This stage signifies our adaptation to our surroundings and sustained learning that are unintended and unavoidable.

Second level is Integrative learning. In this stage, the student learns the basic overview of all of the academic fields and how they are related. The best way is to learn by topics. This stage of learning is appropriate for elementary and middle school education.

The third level is Multidisciplinary learning. This stage allows the student to learn a specific field and how they are related to real life. The best method is to learn the practical uses. This is appropriate for middle school education.

The fourth level is Discipline learning. This stage focuses on each educational stage and is appropriate for middle school education.

The last fifth level is Content Specific learning. This stage deals with detailed research of each field and is appropriate for high school and professional education. 
Therefore, STEAM education does not entail a part of education but refers to an overall paradigm from the professional learning to lifelong learning, which is organized with the addition of art to the existing education, especially in the integrated education of Science, Technology, Engineering, Mathematics and Art in elementary school education.

\subsection{Need for STEAM Education}

As the low interests and accomplishments of American teenagers in math and science, the STEM education started as an educational solution. However, the STEM education was missing a very important piece. This is that Art, a comparatively competitive and innovative field as STEM in creativity, was also needed. In addition, the science education could not keep up with the current changes in science, technology, and engineering and the teenagers who are used to the various advanced technology products were bound to lose interests as well as creating a gap in creativity cultivation in science education during elementary and middle school years.

Therefore, the experts argued for "amicability between science and art" because a dichotomous thought that art is illogical and science is not creative ruined the future and the art and science should be taught together before the concept of STEAM education emerged. In this perspective, the art education is crucial in developing creativity that is highly valued in modern education; therefore, the art education should be added to the education of science, technology, engineering, and mathematics.

\section{Factors to Realize Successful STEAM Education Materials}

To realize the STEAM education, the factors on how to interrelate and integrate science, technology, engineering, art, and mathematics as well as the factors that are needed in realizing the STEAM education in creativity in addition to the considered factors in contents need to be decided, which in reality, makes the creation of STEAM materials into a system science or system engineering. In other words, the many factors need to harmonize in a creative and appropriate way along with the theoretical foundation and applications in a systematic way.

Many questions on STEAM education include whether only $\mathrm{S}$ and $\mathrm{T}$ or $\mathrm{T}$ and $\mathrm{E}$ could be realized, how it is different from the field trips to research centers or science centers, and how different it is from the existing STS education.

First, the materials of STEAM education could hold an important meaning. Therefore, whether to start from current textbook science theories and systematically increase into the engineering and technology or whether to create a new structure of reverse engineering on a topic to allow students find the theories as they dissemble a product could be an issue but to smoothly transition to STEAM project with minimal friction, the former would be more preferable than the latter. This is because if the reverse engineering is utilized for the concept understanding in science education, the students may not fully understand the science theories and may require additional curricular activities. 
In reality, the reflecting factors of $\mathrm{S}, \mathrm{T}, \mathrm{E}, \mathrm{A}$, and $\mathrm{M}$ in STEAM education are naturally included in the systematic connection based on a key factor of storytelling and the process to describe the variety of science technology engineering. Therefore, the most important yet the most difficult part in STEAM content organization is how to realize the following 7 basic concepts in each section.

\section{1) Connection, combination and fusion}

To apply on site without creating conflicts with current curriculum, a systematic connection into the basic science technology engineering is required. In addition, integrative thought or fused thought activities could be organized separately or together with each area of STEAM.

2) Introduction of variability for a creative STEAM education through diverse thoughts on science technology engineering. For creative diverse thoughts, the factors that educate students on how the basic scientific theory can be applied in various technologies and how these are used in diverse ways in real life through engineering are necessary. Therefore, the systematic connection between the STEAM areas in STEAM education and the education and activities on the diverse applications of the areas are crucial in a creative education.

3) For an efficient and creative teaching, the teachers require various creative tools. In creative STEAM education, the development of various creative methods, creative learning tools, and creative experiments is important. However, the term, creative experiment, is being overused currently. The experiments in creative sciences should be based on the STEAM concept.

4) One of the key STEAM educations is cultivating the ability to see the big picture, or the ability to be able to see the forest along with the trees.

5) In the rapidly changing world of integrative technology, science, technology and engineering of 10 years past can be meaningless. Therefore, one of the key factors of STEAM education is just in time education that rapidly responds to the changing integrative technology.

6) First, STEAM education will be a practical and realistic education that can predict the future in a systematic way based on the science technology and engineering as well as the connections to politics, environment, society, economy, and pursuit of values with integrative thoughts and creativity.

7) The integrative design concept in engineering could be an important spirit in STEAM education. The integrative design concept on the group works for the STEAM can be introduced to cultivate the abilities to become ethical, social, cooperative, leading, and considerate and communicative among the students as well as the systematic experiment abilities in science, technology and engineering, which will not only cultivate the scientists, technologists, or engineers with the right character and practical abilities and also the future politicians and social leaders in various areas. 
The other factors to consider in STEAM contents development other than the key basic factors are the introductions of STEAM education concept to cultivate creative talents who will contribute to the global society. In other words, it is to cultivate global talents with international senses based on integrative STEAM knowledge in science, technology, and engineering that will consider the anthropological culture, history, politics, economy, and environment and also solve the issues with highly ethical thoughts and science, technology, and engineering. The global integrative talents desired by the current world are people with ethics, strategies, creativity, challenging minds, and sacrificial decision-making abilities. Ultimately, the STEAM education attempts to create integrative science technology talents as a global leader with high ethical standards and minds to harmoniously manage the nature and humans. The basic skills to manage the modern science technology engineering are emphasized in STEAM education. This STEAM education is the driving power for the future and a crucial education system to gain higher grounds in the global competition.

\section{Example : EPL-Based STEAM Education}

This is example of STEAM education using IT-based EPL. Contents are as follows.

1) Review

- Teacher (T): Let's talk about what we learned last time.

- Student (S): (Talks about what they learned last time.)

2) Motivation

- T: Let's watch how to draw the bracken with a computer program. (Shows the picture of bracken and the fractal shape realization process.)

- S: (Watches the videos.)

- T: Let's watch how to draw the snowflakes with the computer program. (Shows the picture of snowflakes and the Koch snowflake fractal realization process.)

- S: (Watches the videos.)

3) Learning Objectives and Learning Activities

- T: Let's talk about the learning objectives.

- T: Let's talk about the learning activities.

$<$ Learning Activities $>$

- Activity 1: Hey, logo! Listen to me!

- Activity 2: Drawing shapes

4) Activity 1: Hey, logo! Listen to me!

- T:Let's talk about the basic screen of the logo program. (Screen organization, command enter window, realization screen, etc.)

- S:(Learns the screen organization.) 
- T: Let's talk about the commands of the logo program. (Allow the students to easily understand the commands, such as fd, bk, rt, lt, home, cs, ct, pu, pd, and setpc through the realization screen and allow the students to practice.)

- S:(Learns the basic commands.)

- T: Let's draw simple shapes with the commands with me. (Teach the students to draw simple shapes (many triangles, simple rectangles, etc) with basic commands.)

- S: (Draws simple shapes using the basic commands.)

5) Activity 2: Drawing shapes

- T:Let's draw the shapes on your own using the logo program. First, use the contruction paper to create the shape you want. Do not use curves and make sure to have more than 6 angles. (Teacher shows an example with a large piece of paper.) When you are coming back to the original point, use the command "home" instead of fd, bk, rt, or lt.

- S: (Makes the individual shapes with construction paper and a pair of scissors and then uses the logo program to realize it on the screen.)

- T: If you are done making your own shapes with the logo program, make the shapes that I am giving you. (Reward the top3 based on their accomplishment.)

- S: (Realizes the difficult shapes onto the screen.)

6) Ending and Preview

- T:Let's talk about what we learned today.

- S: We learned about the logo program./ We learned the basic commands of the logo program./ We drew shapes onto the screen, etc.

- T: We will learn (next content) next time we meet.

Accomplishment standards: Can the student understand the use the basic commands of logo program?

- high: understands the basic commands of logo programs and uses them well.

- middle: understands and uses the basic commands of logo programs.

- low: cannot understand nor use the basic commands of logo program.

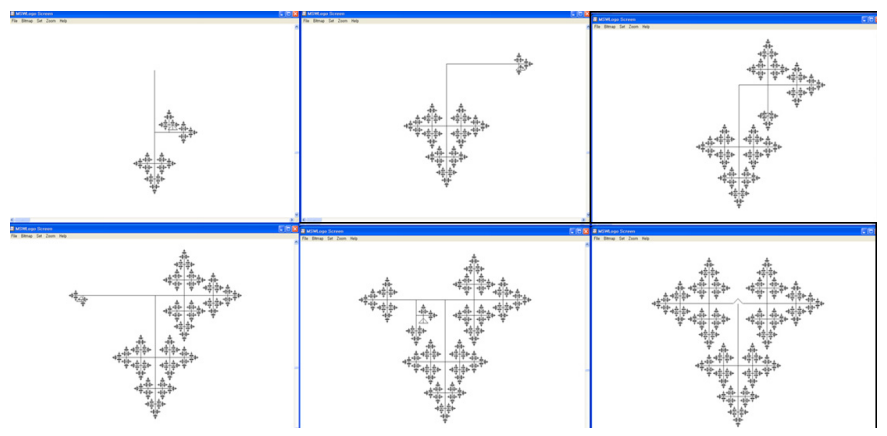

Fig. 1. Fractal geometry screen developed by LOGO Programming 

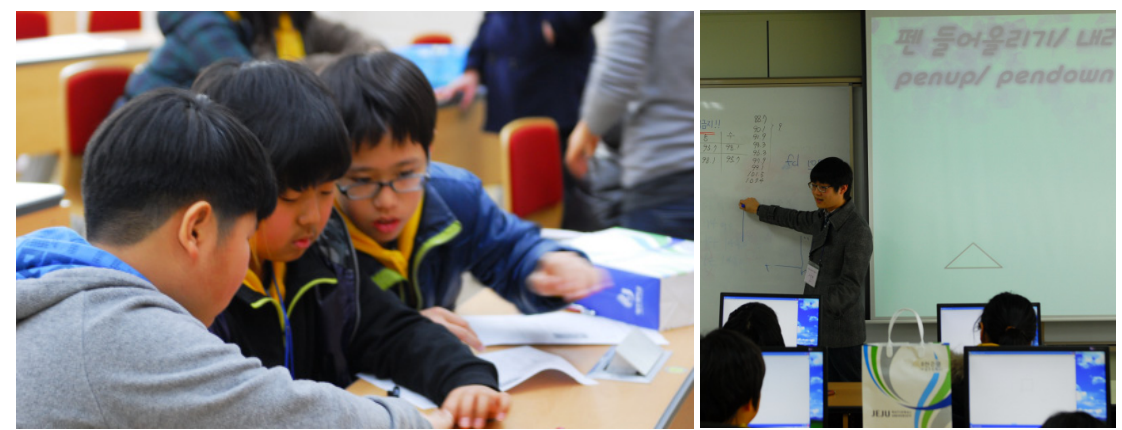

Fig. 2. Students's class working

\section{Conclusion}

To realize the STEAM education, the factors on how to interrelate and integrate science, technology, engineering, art, and mathematics as well as the factors that are needed in realizing the STEAM education in creativity in addition to the considered factors in contents need to be decided, which in reality, makes the creation of STEAM materials into a system science or system engineering. In other words, the many factors need to harmonize in a creative and appropriate way along with the theoretical foundation and applications in a systematic way.

This paper analyzed the statuses of STEAM education. And, suggested factors to realize successful STEAM education materials.

Acknowledgments. This work was supported by the Korea Foundation for the Advancement of Science \& Creativity(KOFAC) grant funded by the Korean Government(MEST).

\section{References}

1. Horton, B.: Integrating Logo into the Secondary Mathematics Curriculum. In: Proceedings of LOGO and Mathematics Education Conference, vol. 5 (1991)

2. Sacristan, A.I.: Exploring infinite processes through Logo programming activities of recursive and fractal figures. In: EUROLOGO Conference, vol. 10 (2005)

3. Park, N., Kwak, J., Kim, S., Won, D., Kim, H.: WIPI Mobile Platform with Secure Service for Mobile RFID Network Environment. In: Shen, H.T., Li, J., Li, M., Ni, J., Wang, W. (eds.) APWeb Workshops 2006. LNCS, vol. 3842, pp. 741-748. Springer, Heidelberg (2006)

4. Park, N.: Security Scheme for Managing a Large Quantity of Individual Information in RFID Environment. In: Zhu, R., Zhang, Y., Liu, B., Liu, C. (eds.) ICICA 2010. CCIS, vol. 106, pp. 72-79. Springer, Heidelberg (2010)

5. Park, N.: Secure UHF/HF Dual-Band RFID: Strategic Framework Approaches and Application Solutions. In: Jędrzejowicz, P., Nguyen, N.T., Hoang, K. (eds.) ICCCI 2011, Part I. LNCS, vol. 6922, pp. 488-496. Springer, Heidelberg (2011) 
6. Park, N.: Implementation of Terminal Middleware Platform for Mobile RFID computing. International Journal of Ad Hoc and Ubiquitous Computing 8(4), 205-219 (2011)

7. Toenisson, E.: Programming language LOGO in school mathematics and teacher training. In: Proceedings of PME Conference, vol. 21(1) (1997)

8. Freiermuth, K., Hromkovič, J., Steffen, B.: Creating and Testing Textbooks for Secondary Schools An Example: Programming in LOGO. In: Mittermeir, R.T., Sysło, M.M. (eds.) ISSEP 2008. LNCS, vol. 5090, pp. 216-228. Springer, Heidelberg (2008)

9. Park, N., Kim, Y.: Harmful Adult Multimedia Contents Filtering Method in Mobile RFID Service Environment. In: Pan, J.-S., Chen, S.-M., Nguyen, N.T. (eds.) ICCCI 2010, Part II. LNCS (LNAI), vol. 6422, pp. 193-202. Springer, Heidelberg (2010)

10. Park, N.: Customized Healthcare Infrastructure Using Privacy Weight Level Based on Smart Device. In: Lee, G., Howard, D., Ślęzak, D. (eds.) ICHIT 2011. CCIS, vol. 206, pp. 467-474. Springer, Heidelberg (2011)

11. Park, N.: Secure Data Access Control Scheme Using Type-Based Re-encryption in Cloud Environment. In: Katarzyniak, R., Chiu, T.-F., Hong, C.-F., Nguyen, N.T. (eds.) Semantic Methods. SCI, vol. 381, pp. 319-327. Springer, Heidelberg (2011)

12. Park, N., Song, Y.: Secure RFID Application Data Management Using All-Or-Nothing Transform Encryption. In: Pandurangan, G., Anil Kumar, V.S., Ming, G., Liu, Y., Li, Y. (eds.) WASA 2010. LNCS, vol. 6221, pp. 245-252. Springer, Heidelberg (2010)

13. Park, N.: The Implementation of Open Embedded S/W Platform for Secure Mobile RFID Reader. The Journal of Korea Information and Communications Society 35(5), 785-793 (2010) 